\title{
A LbL-Assembled Bioactive Coating Modified Nanofibrous Membrane for Rapid Tendon-Bone Healing in ACL Reconstruction
}

This article was published in the following Dove Press journal: International Journal of Nanomedicine

\author{
Fei Han' \\ Peng Zhang ${ }^{2}$ \\ Tianwu Chen ${ }^{2}$ \\ Chao Lin' \\ Xuejun Wen' \\ Peng Zhao' \\ 'Institute for Translational Medicine, \\ Institute for Biomedical Engineering and \\ Nanoscience, Shanghai East Hospital, \\ Tongji University School of Medicine, \\ Shanghai, 200092, People's Republic of \\ China; ${ }^{2}$ Department of Sports Medicine, \\ Huashan Hospital, Fudan University, \\ Shanghai, 200040, People's Republic of \\ China
}

Correspondence: Peng Zhao; Peng Zhang Institute for Translational Medicine, Institute for Biomedical Engineering and Nanoscience, Shanghai East Hospital, Tongji University School of Medicine, Tongji University, Room 222, Shixun Building, Shanghai 200092, People's

Republic of China

Tel +862165988029

Fax +86 21 65983708-0

Email zp@tongji.edu.cn;

zhangpengym@I63.com
Introduction: In anterior cruciate ligament (ACL) reconstruction, hamstring tendon autograft is a well-accepted surgical choice as an alternative ACL graft. But the main disadvantage of autograft is its inefficient healing with host bone-tunnel which will leading to surgery failure.

Methods: A biomimetic nanofibrous membrane for tendon-bone integration is fabricated in this work, which is composed of polycaprolactone (PCL) electrospinning membrane and chitosan/hyaluronic acid (CS/HA) multilayers film.

Results: By using layer-by-layer (LbL) self-assembly this functional CS/HA multilayer films are deposited on the surface of PCL nanofiber to enable the local delivery of stromal cell-derived factor-1 $\alpha$ (SDF-1 $\alpha)$ and bone morphogenetic protein-2 (BMP-2) in tendon-bone interface. This membrane can promote cell proliferation and recruitment, as well as inducing the osteogenic differentiation and recruitment of BMSCs.

Conclusion: Further in vivo studies demonstrate that to wrap the tendon autograft using the membrane may afford superior tendon-bone integration and inhibit scar tissue formation in a rabbit ACL reconstruction model. More importantly, the biomechanical properties of the tendon-bone interface have been improved. This study shows that this biomimetic nanofibrous membrane is effective for improving tendon-bone healing after ACL reconstruction surgery.

Keywords: anterior cruciate ligament reconstruction, tendon-bone healing, layer-by-layer self-assembly, nanofibrous membrane, stromal derived factor- $1 \alpha$

\section{Introduction}

The clinical treatment of knee anterior cruciate ligament (ACL) injury caused by highrisk sports, over-exercise or accidents is still a great challenge. ${ }^{1,2}$ As ACL plays an important role in the stability of the knee joint, ACL injury can lead to knee instability and a high risk of osteoarthritis (OA) ${ }^{3,4}$ Due to the limited regenerative capacity of the ACL, pursuing suitable grafts for its reconstruction has always been a goal of sport medicine. In ACL reconstruction surgery, hamstring tendon autografts are widely chosen as alternative ACL grafts due to advantages such as low risks of arthropathy and donor-site lesions. ${ }^{5,6}$ However, the main disadvantage of an autograft is its inefficient integration with the host bone tunnel, which will result in long postoperative healing time, graft sliding and bone loss in the bone tunnel during movement and will finally lead to surgery failure. ${ }^{7,8}$ The poor integration process of autografts and bone tunnels is ascribed to the rapid cell proliferation of fibroblasts compared to that of osteoblasts, which results in the formation of scar tissue with poor biomechanical properties at the tendon-bone interface, eventually leading to inefficient integration. ${ }^{9}$ 
Therefore, investigation into novel scaffolds to promote bone tissue formation and tendon-bone interface integration in the tunnel is necessary for the improvement of biomechanical function and postoperative recovery.

The tissue engineering approach provides new ideas for solving this problem. Previous studies have confirmed that some bioactive scaffolds, such as decellularized scaffolds, ${ }^{10,11}$ electrospun scaffolds ${ }^{12,13}$ and collagen sponges, ${ }^{14,15}$ promote tendon-bone healing. Among them, the preparation of electrospinning scaffolds is simple and the cost is low. These scaffolds can simulate the extracellular matrix and constituted a 3D-culture environment of cells, which made it widely used for repairing the injuries of connective tissues. ${ }^{12,16,17}$ In our previous study, we designed a polycaprolactone nanofibrous scaffold doped with nanohydroxyapatite to wrap autologous tendon for ACL reconstruction in a rabbit model. ${ }^{12}$ The results confirmed that this scaffold can effectively promote the proliferation and mineralization of osteoblasts, reduction of fibrous scar tissue at the tendon-bone interface, and improvement in biomechanical properties. However, this scaffold has limited effects on the early healing of the tendon-bone interface, and further improvements are needed. In recent years, researchers have paid increasing attention to the synergistic effect of stem cell recruitment derived from chemotactic factors and growth factors. For example, some studies confirmed that the synergistic interaction of stromal cell-derived factor-1 $\alpha$ (SDF-1 $\alpha)$ with bone morphogenetic protein-2 (BMP-2) can promote bone marrow stromal cell (BMSC) homing and new bone formation. ${ }^{18-20}$ Therefore, the strategy of locally delivering SDF- $1 \alpha$ can overcome many of the shortcomings of clinical applications of exogenous stem cell transplantation.

In this work, a dual-growth-factor delivery system consisting of SDF-1 $\alpha$ - and BMP-2-loaded chitosan/hyaluronic acid (CS/HA) multilayer coatings was manufactured using layer-by-layer (LbL) self-assembly (Figure 1). LbL self-assembly system has recently been explored as a convenient and green drug controlled release system. ${ }^{21}$ Functional, polyelectrolyte multilayer films were deposited on the surface of nanofibers to render the latter more biomimetic and enable the local delivery of growth factors. A polyelectrolyte multilayer film is a LbL build-up of oppositely charged polyelectrolytes to form a nano/microscale film that acts as a reservoir to retain the bioactivity of electrostatically adsorbed molecules. As Chitosan (CS) and hyaluronic acid (HA) are biocompatible materials which were widely used in bone tissue engineering, ${ }^{22,23}$ in this work, we selected CS and HA as the polyelectrolytes for LbL self-assembly. The primary objective of this

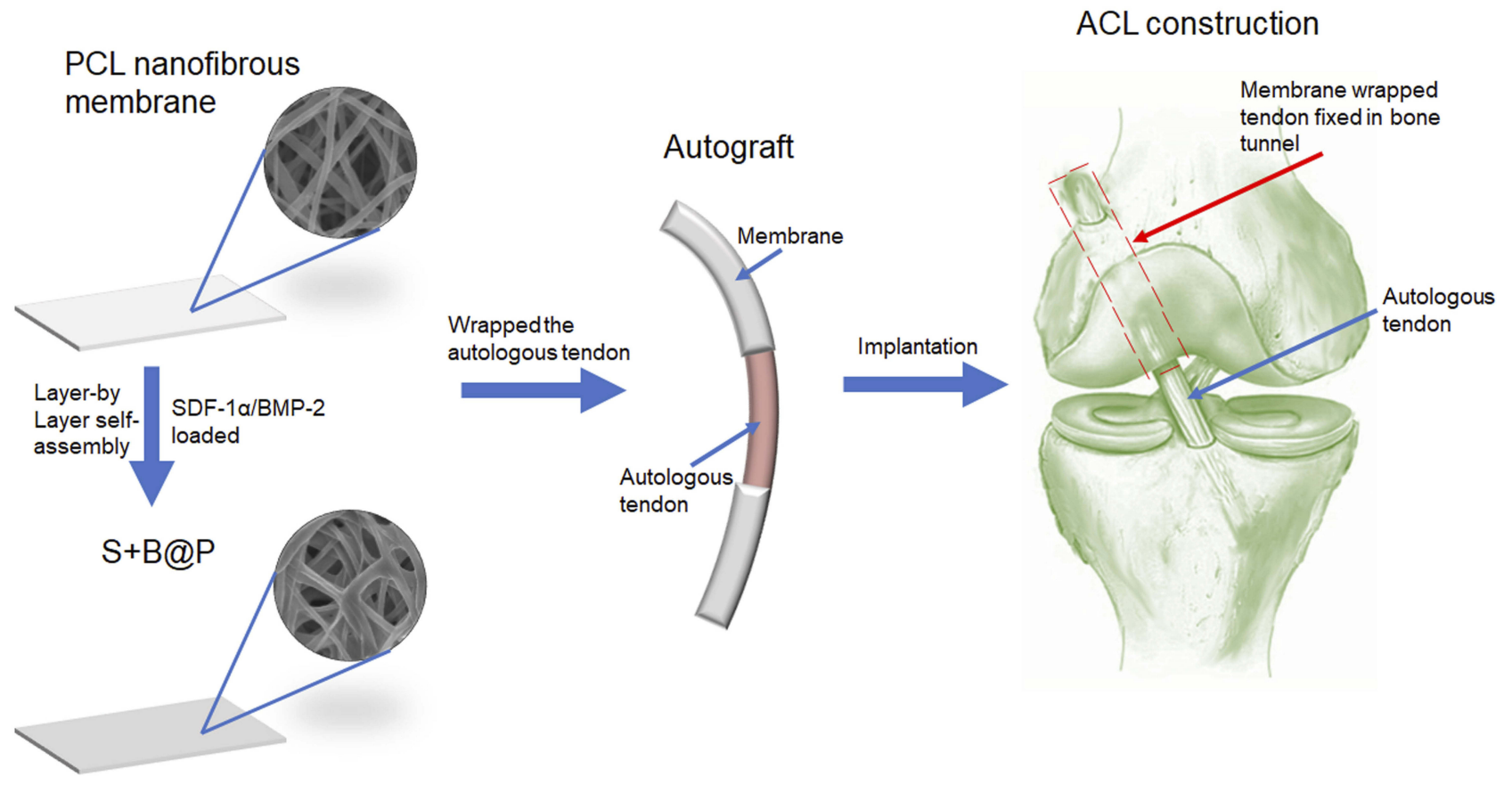

Figure I Schematic illustration of the fabrication of nanofibrous membrane, and the implantation of the membrane-wrapped autograft tendon into femur and tibia bone in $A C L$ reconstruction surgery.

Abbreviations: SDF-I $\alpha$, stromal derived factor-I $\alpha$; BMP-2, bone morphogenetic protein-2; ACL, anterior cruciate ligament. 
study was to investigate whether a delivery system of SDF- $1 \alpha$ and BMP-2 could be fabricated using LbL selfassembly and could thus have the potential to induce osteogenic differentiation and recruitment of BMSCs. The secondary objective was to investigate whether this scaffold could enhance tendon-bone interface integration and inhibit scar tissue formation. Therefore, the effects of the scaffold on the bio-activities of BMSCs in terms of their recruitment, proliferation and osteogenic differentiation were evaluated in vitro. Moreover, a rabbit ACL injury model was employed in this study for in vivo ACL reconstruction, and biomechanical and histological analyses were applied for a comprehensive follow-up evaluation in vivo.

\section{Materials and Methods Materials}

The reagents for electrospinning, PCL $(\mathrm{Mw}=80 \mathrm{kDa})$, dichloromethane and dimethyl sulfoxide (DMSO), were purchased from Sigma-Aldrich (USA). The reagents for LbL self-assembly, polyallylamine hydrochloride (PAH), CS $(\mathrm{Mw}=50-190 \mathrm{kDa})$ and HA $(\mathrm{Mw}=1500-1800 \mathrm{kDa})$ were also obtained from Sigma-Aldrich (USA). Dulbecco's modified Eagle's medium (DMEM), PBS, Fetal bovine serum (FBS), penicillin-streptomycin and trypsin were purchased from Gibco (USA). Recombinant human BMP-2 (rhBMP-2) and recombinant human SDF-1 $\alpha / \mathrm{CXCL1} 2$ were purchased from Peprotech (USA).

\section{Fabrication of Nanofibrous Polycaprolactone (PCL) Membrane}

Using a conventional electrospinning method, random nanofibrous PCL scaffolds were manufactured. Briefly, a polymer solution was prepared by dissolving PCL in a mixture of dichloromethane/DMSO $(3: 1, \mathrm{w} / \mathrm{w})$ at a concentration of $6 \%$ $(\mathrm{w} / \mathrm{w})$. The PCL solution was placed into a $10-\mathrm{mL}$ glass syringe, and then the syringe was fixed to a pump (LSP011A, Longer Pump Inc., People's Republic of China) to control the flow speed at a constant rate $(0.5 \mathrm{~mL} / \mathrm{h})$. A high voltage $(15 \mathrm{kV})$ was applied to the needle tip, and the distance between the tip and the nanofiber collector was $20 \mathrm{~cm}$. The collector for the PCL nanofibers was an aluminum foil-covered cylinder rotating at $100 \mathrm{rpm}$. The PCL nanofiber membranes were collected from the aluminum foil and sterilized with ethanol overnight before they were ready for further use. The PCL nanofibrous scaffolds utilized in this study were of similar thickness.

\section{Preparation of the Growth Factor-Loaded Membrane}

The CS/HA multilayer film-coated PCL scaffold was prepared using an LbL self-assembly method. Briefly, solutions of polyallylamine hydrochloride (PAH, $1 \mathrm{mg} / \mathrm{mL}$ ), CS ( $1 \mathrm{mg} / \mathrm{mL}$, with $1 \mathrm{mM}$ acetic acid), and HA $(1 \mathrm{mg} / \mathrm{mL}$, $\mathrm{pH}$ 4.7) were prepared. LbL was used to coated the nanofibrous scaffold with a CS/HA multilayer film loaded with positively negatively charged $\mathrm{SDF}-1 \alpha$ and positively charged rhBMP-2 at $\mathrm{pH}$ 4.7. Briefly, the PCL membrane was initially immersed in the PAH solution for $1 \mathrm{hr}$ to form a positively charged precursor layer, which then initiated the LbL assembly process. Then, the PCL membrane was soaked in a solution of SDF-1 $\alpha(1 \mu \mathrm{g} / \mathrm{mL})$ and HA for 5 mins, and the membrane was subsequently soaked in a solution of rhBMP-2 $(1 \mu \mathrm{g} / \mathrm{mL})$ and CS. This process was repeated 10 times to coat the PCL nanofibers with the SDF-1 $\alpha / \mathrm{BMP}-2$-loaded CS/HA multilayer film. This scaffold loaded with BMP-2 and SDF-1 $\alpha$ was denoted as $\mathrm{S}+\mathrm{B} @ \mathrm{P}$. In addition, as the BMP-2-loaded scaffold is a widely studied classic scaffold for bone repair, we fabricated a BMP-2-loaded PCL scaffold as a positive control (denoted as a $\mathrm{B} @ \mathrm{P}$ ) to illustrate the advantages and clinical applicability of S+B@P. Briefly, after the PAH-derived positively charged precursor layer formed, the PCL membrane was soaked in the HA solution without SDF-1 $\alpha$ for 5 mins, and then the membrane was soaked in a solution of rhBMP-2 $(1 \mu \mathrm{g} / \mathrm{mL})$ and CS. This process was repeated 10 times, and a CS/HA multilayer film loaded with a single growth factor (BMP-2) was fabricated. The abbreviations of the scaffolds used in this work are summarized in Table 1.

\section{Characterization of Scaffolds}

The $\mathrm{S}+\mathrm{B} @ \mathrm{P}$ and $\mathrm{B} @ \mathrm{P}$ specimens, as well as the untreated PCL membranes, were sputter-coated with gold. Then, their micromorphology was visualized under scanning electron microscopy (SEM) (S3000N, Hitachi, Japan) at

Table I Sample Abbreviations Used in This Work

\begin{tabular}{|l|l|}
\hline $\begin{array}{l}\text { Name of } \\
\text { Sample }\end{array}$ & Description of Sample \\
\hline PCL & Nanofibrous PCL scaffold \\
\hline B@P & BMP-2-loaded CS/HA multilayer-modified PCL scaffold \\
\hline S+B@P & $\begin{array}{l}\text { SDF-l } \alpha \text { - and BMP-2-loaded CS/HA multilayer- } \\
\text { modified PCL scaffold }\end{array}$ \\
\hline
\end{tabular}


an accelerating voltage of $15 \mathrm{kV}$. The average fiber diameter of each specimen was measured using ImageJ software after the micrographs were obtained $(n=3)$. An average of 100 fibers were counted for each specimen. In addition, a thin piece was removed from each sample and placed on copper meshes. Then, the structure of each group was observed under a transmission electron microscope (TEM) (JEM-2100F, JEOL, Japan)

The deposition of polyelectrolytes (CS/HA) on the nanofibers of $\mathrm{S}+\mathrm{B} @ \mathrm{P}$ and $\mathrm{B} @ \mathrm{P}$ after the LbL selfassembly was evaluated using an attenuated total reflection-Fourier transform infrared (ATR-FTIR) spectrometer (Tensor 27, Bruker, Woodlands, TX, USA) and a UV-vis spectrophotometer (Carry 50, Varian).

The hydrophilicity of each group was detected by water contact angle (WCA) analysis based on a Model 200 video. Briefly, the PCL, S+B@P and B@P membranes were cut into a size of $5 \mathrm{~cm} \mathrm{x} 5 \mathrm{~cm}$ and flattened. Then, a $1 \mu 1$ water droplet was placed on the surface of the sample, and the instrument's video recorder was used to observe the interaction between the water droplet and the material interface within one minute. The WCA was calculated using the VCA Optima software.

The scaffolds of each group were cut into a size of $1 \mathrm{~cm} \times 1 \mathrm{~cm}$ and soaked in $1 \mathrm{~mL}$ of phosphate-buffered saline (PBS) at $37^{\circ} \mathrm{C}$. The PBS samples were collected and replaced with fresh PBS daily, such samples were immediately frozen at -80 . The amount of SDF- $1 \alpha$ and rhBMP- 2 released in PBS was measured by an ELISA kit (Peprotech, USA) for 50 days $(n=3)$. PBS samples from the release studies were thawed and returned to room temperature immediately prior to their use. ELISA was performed in accordance with the instructions provided with the development kit. Color monitoring of the ELISA plates was performed using a PerkinElmer Victor3 multilabel reader with a $405 \mathrm{~nm}$ filter and $650 \mathrm{~nm}$ correction filter.

\section{In Vitro Studies}

\section{Cell Proliferation and Migration}

SD rat BMSCs were purchased from the Cell Bank of the Chinese Academy of Sciences (Shanghai, People's Republic of China). The scaffolds of each group were cut into circular films with a diameter of $1.6 \mathrm{~cm}$ and then pasted on the bottom of a 24 -well plate. The BMSCs $(1 \times 105$ cells/well $)$ were seeded in each well and cultured in Dulbecco's modified Eagle's medium (DMEM) containing 10\% foetal bovine serum (FBS) and $1 \%$ penicillin/streptomycin. BMSC proliferation was evaluated using the Cell Counting Kit- 8 assay (CCK-8,
Dojindo Molecular Technologies, Inc., Kumamoto, Japan) after 1, 3 and 5 days of culture according to the manufacturer's protocol. Briefly, the cells were washed twice by PBS, and then treated with $500 \mu \mathrm{L}$ CCK-8 working solution $(500 \mu \mathrm{L}$ DMEM containing $10 \%$ WST- 8 solution(v/v)). After the plates incubated at $37^{\circ} \mathrm{C}$ for $2 \mathrm{~h}, 200 \mu \mathrm{L}$ of resulting solution in each well was transferred to a 96-well plate. Optical density (OD) value at $540 \mathrm{~nm}$ was recorded with a micro-plate reader (Victor X, PerkinElmer).

Additionally, the morphology of BMSCs cultured on the scaffold was observed by SEM. Briefly, the BMSCs were cultured on the scaffolds for $24 \mathrm{hrs}$. Then, the cells were washed twice with PBS and immersed in PBS containing $1 \%$ glutaraldehyde for $4 \mathrm{hrs}$. They were then dehydrated in ethanol solutions at concentrations of $20 \%$, $40 \%, 60 \%, 80 \%$, and $100 \%$ and finally dried at $25^{\circ} \mathrm{C}$. The sample was gold sputtered under vacuum and visualised under SEM (S3000N, Hitachi, Japan).

An in vitro BMSC migration model based on Transwell (Corning) was established. Briefly, $100 \mu \mathrm{l}$ cell suspensions of BMSCs with a density of $50,000 / \mathrm{mL}$ were added to the upper chamber of each Transwell insert. After 24 and $48 \mathrm{hrs}$ of culture, the polycarbonate membrane was removed, and the unmigrated cells on the membrane were gently removed. Then, the membrane was immersed in a $2.5 \%$ glutaraldehyde solution for $2 \mathrm{hrs}$, and the migrating cells were subsequently stained using $0.5 \%$ crystal violet solution for 10 mins. The migrating cells were observed using a microscope, and 6 fields per well were randomly selected and photographed. Subsequently, the number of cells was counted using ImageJ software.

\section{Alkaline Phosphatase (ALP) and Alizarin Red Staining (ARS) Analysis}

The capability of PCL, B@P and S+B@P to induce the osteogenic differentiation of BMSCs was assessed by ALP and ARS analysis. Briefly, the membranes of each group were cut into circular films with a diameter of $1.6 \mathrm{~cm}$ and then pasted on the bottom of a 24-well plate. The BMSCs $(1 \times 105$ cells/well) were seeded in each well and cultured in osteogenic induction medium (OIM: $\beta$-glycerol phosphate, dexamethasone and ascorbic acid supplemented in full DMEM). After 7 days of culture, the level of ALP secretion was evaluated by an ALP staining kit and ALP quantification kit (Beyotime Biotechnology Inc., Shanghai, People's Republic of China). After 30 days of culture, the level of mineralised deposition of the BMSCs was evaluated by ARS staining. The cells were fixed in $70 \%$ ethanol for $1 \mathrm{hr}$. After washing twice with 
double-distilled $\mathrm{H} 2 \mathrm{O}\left(\mathrm{ddH}_{2} \mathrm{O}\right)$, the BMSCs were stained with an ARS solution ( $\mathrm{pH}=4.8)$ for 30 mins. After staining, the cells were washed using $\mathrm{ddH}_{2} \mathrm{O}$ and then air dried at room temperature. After 30 days of culture, the level of mineral deposition was evaluated by an ARS staining kit (Solarbio, Beijing, People's republic of China). The ALP- and ARS-stained cells were observed using a microscope, and 6 fields per well were randomly selected and photographed. After the photographs were taken, the ARS-stained mineral deposition was desorbed with $10 \%$ cetylpyridinium chloride (Sigma-Aldrich). The solution was collected, and optical density was recorded at $540 \mathrm{~nm}$ with a spectrophotometer (Multiskan MK3, Thermo Fisher).

\section{In Vitro Real-Time Polymerase Chain Reaction (PCR) Analysis}

To clarify the influence of different scaffolds on osteogenic differentiation in vitro, the gene expression levels of runtrelated transcription factor 2 (Runx2), collagen I (Col I), osteopontin (OPN) and osteocalcin (OCN) were detected in the PCL, B@P and S+B@P groups after 7 and 14 days after BMSCs seeded on the scaffolds, respectively. Total tissue RNA was extracted with the TRIzol reagent (Invitrogen Inc., Carlsbad, CA, USA) according to the instructions for phenol chloroform-isoamyl alcohol extraction. RNA (1000 ng) was placed into a $20 \mu \mathrm{L}$ reaction system for reverse transcription with the PrimeScript RT reagent kit (Takara) according to the manufacturer's instructions. Real-time PCR was performed using the SYBR Green PCR Master Mix (Takara) on a realtime PCR System (Applied Biosystems 7500). The primer sequences used in this study were designed as follows: Runx2 forward 5'-TCTTCCCAAAGCCAGAGCG-3' and reverse 5'-TGCCATTCGAGGTGGTCG-3'; Col I forward 5'TGGATGGCTGCACGAGT-3' and reverse 5'-TTGGGATG GAGGGAGTTTA-3'; OPN forward 5'-GAGGAGAAGGC GCATTACAG-3' and reverse 5'-AAACGTCTGCTTGTCT GCTG-3'; OCN forward 5'-CATGAAGGCTTTGTCAGA CT-3' and reverse 5'-CTCTCTCTGCTCACTCTGCT-3'; GAPDH forward 5'-GGCAAGTTCAACGGCACAGT-3' and reverse 5'-GCCAGTAGACTCCACGACAT-3'. Each quantitative PCR run was performed with at least three experimental replicates, and the relative expression level of each gene was calculated using the $2^{-\Delta \Delta \mathrm{Ct}}$ method.

\section{In Vivo Studies}

\section{ACL Reconstruction Animal Models}

The animal study was approved by The University of Fudan Institutional Animal Care and Use Committee and conducted according to the Guide for the Care and Use of Laboratory Animals of Fudan University. The procedure of the ACL reconstruction surgery is illustrated in Figure 2. Briefly, 48 skeletally mature female New Zealand white rabbits (12 weeks old, $2.4 \pm 0.3 \mathrm{~kg}$ ) were used and divided into three groups (PCL, B@P and S+B@P) with six rabbits in each group. Under general anaesthesia, the bilateral limbs were shaved and disinfected. Then, skin incisions were made to expose the right knee joint of the rabbit, and lateral parapatellar arthrotomy was subsequently used. As shown in Figure 2, the native ACL was exposed after removing the soft tissue surrounding the ACL. Then, the native ACL was removed from the insertion sites by sharp dissection. A bone tunnel $2.5 \mathrm{~mm}$ in diameter was created with a drill in the femur and tibia insertion sites of the native ACL. The contralateral semitendinosus tendon was harvested and wrapped with the membrane. The semitendinosus tendon wrapped with the PCL membrane was used as the control group. The prepared graft was passed through the bone tunnel and joint cavity. Both ends of the graft were attached to the adjacent periosteum and soft tissue with two 4-0 Ethibond sutures (Johnson \& Johnson, New Brunswick, NJ, USA), and the wound was then closed. After the surgical procedure, the rabbits were kept in large cages without influencing their movement to prevent joint stiffness. After 4 and 8 weeks post-surgery, the rabbits were sacrificed to harvest tissue samples for histological and biomechanical analysis. The interface healing between the engineered tendon and host tissue was also examined.

\section{Histological Analysis}

After the rabbits were sacrificed, the knee joint samples were removed and fixed in $10 \%$ neutral buffered formalin for 3 days and were then dehydrated through an alcohol gradient $(30 \%-100 \%)$ and embedded in paraffin wax. The specimens were cut to a thickness of $5 \mu \mathrm{m}$ along the longitudinal axis of the tendon. These sections were treated with haematoxylin and eosin (H\&E) and Masson's trichrome stain (Masson's) for histological evaluation. The sections stained with H\&E and Masson's were observed using a light microscope (Eclipse 80i, Nikon), and the images were captured using a camera (DS-5M, Nikon). For immunohistochemistry staining, endogenous peroxidase was blocked by incubation with $3 \%(\mathrm{v} / \mathrm{v})$ hydrogen peroxide in methanol for 10 mins. Then, the sections were blocked for 20 mins with a blocking reagent containing goat serum in PBS after washing three times with PBS. After overnight incubation at $4^{\circ} \mathrm{C}$ with a primary antibody, the sections 


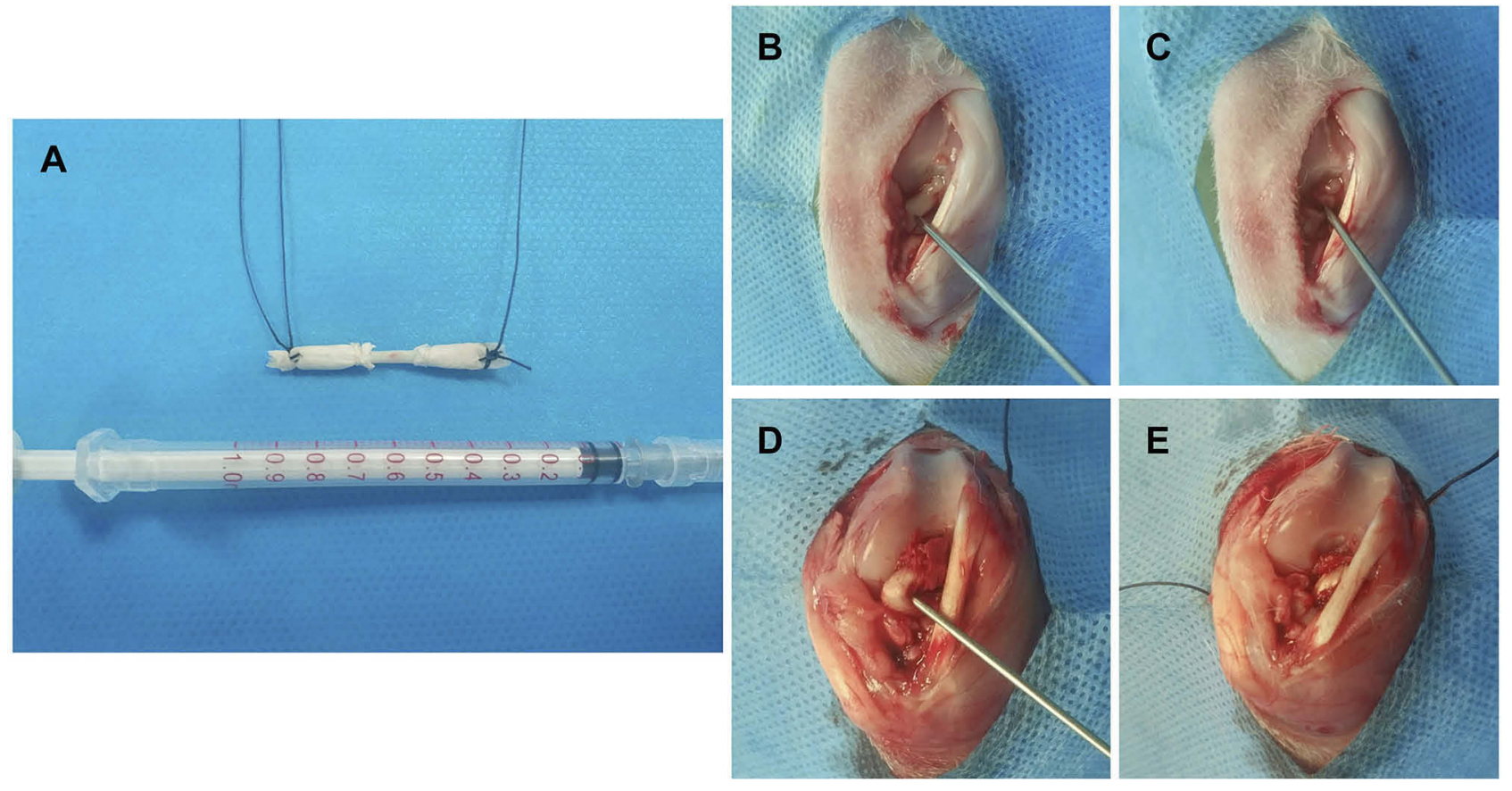

Figure 2 A diagrammatic representation of the procedure of $A C L$ injury modeling and reconstruction surgery.

Notes: (A) Both ends of the autograft (Partial Achilles tendon) were wrapped using the membrane for ACL reconstruction; The procedure of modeling and reconstruction: (B) The ACL tendon was exposed; (C) The ACL tendon tissue was damaged to formatted an ACL injury; (D) \& (E) ACL reconstruction using the membrane wrapped autograft.

were washed and then incubated with a secondary antibody (MaxVision kit; Maixin Biotechnology) for 15 mins at room temperature. Dimethyl aminoazobenzene (DAB) (Simple Stain DAB Solution, Maixin Biotechnology) was used for colour development. Hematoxylin staining was used to reveal the nuclei. The results were evaluated by three individuals who were blinded to the treatments.

\section{Biomechanical Testing}

After sacrifice, the knee joint specimens $(n=4)$ were harvested, and single pull-to-failure analysis was carried out in this experiment. Except for the grafts and tendon, all soft tissue surrounding the ACL was carefully removed from each sample. Care was taken not to damage the connective tissue between the humeral head and tendon. All mechanical testing was conducted using an electronic universal material testing system (AGS-X, Shimadzu, Co., Japan). To reduce slippage, the femur and the tibia were wrapped in saline-moistened gauze, followed by fixation with a restraining jig. Before the tensile test, the samples were preloaded with a static preload of $1 \mathrm{~N}$ for 5 mins. After preconditioning, the ultimate failure load was measured immediately with an elongation rate of $5 \mathrm{~mm} / \mathrm{min}$. After applying a preload of $1 \mathrm{~N}$ with a test speed of $5 \mathrm{~mm} / \mathrm{min}$, the femur-graft-tibia complex underwent preconditioning for a total of 20 cycles. The load-deformation curve was recorded from which the ultimate failure load $(\mathrm{N})$ was measured. Stiffness $(\mathrm{N} / \mathrm{mm})$ was calculated from the slope of the linear region of the load-deformation curve at the maximal load-to-failure point. For each sample, the test was completed when the graft was ruptured.

\section{Statistical Analysis}

The data are expressed as the mean \pm standard deviation from three to four samples. Student's $t$-test was performed to assess statistically significant differences in the results of different experimental groups. Statistical analysis was carried out with the SPSS Statistics 18.0 statistical software package (SPSS Inc., Chicago, IL, USA), and $\mathrm{P}<0.05$ was considered to be statistically significant.

\section{Results \\ Characterization}

The random nanofibrous PCL membrane was fabricated by electrospinning technology, followed by coating of the nanofibers with the CS/HA multilayer complex using LbL self-assembly. To determine the effect of the coated CS/ HA multilayers on the nanofiber structure, the microscopic morphology of all samples was observed by SEM and TEM. As Figure 3A shows, as the CS/HA were assembled 
on the nanofibers, all samples maintained a 3D nanofibrous structure. The morphology of the nanofibers in the $\mathrm{B} @ \mathrm{P}$ and $\mathrm{S}+\mathrm{B} @ \mathrm{P}$ groups was similar to that of the PCL group, but there seemed to be a coating on the surface of the fibers in the $\mathrm{B} @ \mathrm{P}$ and $\mathrm{S}+\mathrm{B} @ \mathrm{P}$ groups. According to the distribution of fiber diameter, the diameter of nanofibers in the $\mathrm{B} @ \mathrm{P}$ and $\mathrm{S}+\mathrm{B} @ \mathrm{P}$ groups increased significantly (from $476.5 \pm 174.1$ to $571.3 \pm 139.6 / 539.6 \pm 209.7$ $\mathrm{nm}$ ), and there was no significant difference between the two groups. The reason for the increase in the fiber diameter of the $\mathrm{B} @ \mathrm{P}$ and $\mathrm{S}+\mathrm{B} @ \mathrm{P}$ groups is that the $\mathrm{CS} / \mathrm{HA}$ coating was assembled on the surface of the nanofibers, which is confirmed by the TEM images (Figure 3B). Obviously, a core-shell structure was fabricated in the $\mathrm{B} @ \mathrm{P}$ and $\mathrm{S}+\mathrm{B} @ \mathrm{P}$ groups due to the $\mathrm{CS} / \mathrm{HA}$ complex deposition.

Through the electrostatic interaction between the amine groups (CS) and the carboxyl group (HA), a CS/HA polyelectrolyte layer was formed. We recorded the changes in the composition of the CS/HA multilayer coating-modified PCL scaffold by ATR-FTIR and UV-vis spectroscopy. As shown in Figure 3C, the ATR-FTIR spectrum of the B@P group demonstrates a distinct absorption at $1605 \mathrm{~cm}^{-1}$, which belongs to the antisymmetric stretching vibration in the carbonyl group of HA. Because CS in the CS/HA multilayers contains an amide II group, this spectrum also shows an absorption at $1556 \mathrm{~cm}^{-1}$, similar to the results of a previous CS/HA complex study. ${ }^{24}$ As shown in the UVvis spectroscopy data (Figure 3D), due to the $-\mathrm{COOH}$ group of HA in the CS/HA multilayers, a distinct absorption peak appeared at $210 \mathrm{~nm}$ after CS/HA was coated on PCL. In addition, the ATR-FTIR and UV spectra of $S$ $+\mathrm{B} @ \mathrm{P}$ are almost the same as those of B@P. These data illustrated that the "shell" coated on the surface of PCL nanofibers was formed by the deposition of CS and HA, which confirmed that we successfully established the CS/ HA multilayers on PCL nanofibers.

The hydrophobicity and hydrophilicity of a scaffold can be detected by a WCA test. The moment at which the water droplets contacted the surface of the scaffold was set to $0 \mathrm{~s}$, and the time from $0 \mathrm{~s}$ to when the droplets were completely absorbed by the scaffold (the WCA was reduced to 0) was recorded. As shown in Figure $3 \mathrm{E}$ and $\mathrm{F}$, at $0 \mathrm{~s}$, the WCA of the $\mathrm{B} @ \mathrm{P}$ group was $41.7^{\circ}$, and that of the $\mathrm{S}+\mathrm{B} @ \mathrm{P}$ group was $48.7^{\circ}$. The water droplets of both groups were completely absorbed within $1 \mathrm{~min}$, while that of the PCL group was maintained at $111^{\circ}$ for a long time. This result indicates that the hydrophilicity of the PCL scaffold was significantly improved after being coated with $\mathrm{CS} / \mathrm{HA}$, which means that the high hydrophilicity of $\mathrm{B} @ \mathrm{P}$ and $\mathrm{S}+\mathrm{B} @ \mathrm{P}$ may be beneficial for cell attachment and growth. The reason for the improvement in hydrophilicity is due to the presence of hydrophilic groups (amine, carboxyl and hydroxyl groups) of the CS/HA multilayer coating. The improvement of hydrophilicity is due to the hydrophilic groups (amine, carboxyl and hydroxyl groups) of the CS/HA multilayer coating. In addition, B@P and $\mathrm{S}+\mathrm{B} @ \mathrm{P}$ show similar characteristics, which means that changing the loaded growth factor seems to have little effect on the properties of the scaffolds.

The release profiles of SDF-1 $\alpha$ and BMP-2 from the scaffolds were investigated using ELISA kits. As presented in Figure $3 \mathrm{H}$, in the $\mathrm{B} @ \mathrm{P}$ group, there was an initial burst release $(48.3 \%)$ in the first three days. On day 10, 79.5\% of BMP-2 was released from the scaffold, and a subsequent stable release of BMP-2 up to 30 days was detected, indicating that the $\mathrm{B} @ \mathrm{P}$ scaffold is capable of maintaining a long-term release of BMP-2. In the S+B@P group (Figure 3G), SDF-1 $\alpha$ and BMP-2 exhibited nearly the same release behavior with initial bursts of $47.3 \%$ and $54.6 \%$, respectively. After 10 days, $81.7 \%$ of total SDF- $1 \alpha$ and $79.4 \%$ of total BMP-2 were released from the scaffold. Therefore, these data demonstrated that the long-term release of single/dual growth factors can be achieved by adding the growth factor into the components via LbL assembly.

\section{Morphology, Osteogenic Differentiation and Migration of BMSCs}

Cell viability and proliferation were evaluated using the CCK-8 kit. As shown in Figure 4D, after the BMSCs were cultured for 7 days on the scaffolds, there was no significant difference in cell viability between the B@P and S+B@P groups, while the viability of the PCL groups was significantly lower than that of the other groups. After 9 days, the cell viability of the $\mathrm{S}+\mathrm{B} @ \mathrm{P}$ group was significantly higher than that of the B@P group. SEM was utilized to observe the morphology of the BMSCs cultured in the scaffold. In Figure 4A, the pseudopods of BMSCs fused with the nanofibers of each group, and these cells showed an extended morphology, while no collapsed morphology or dead cells were observed. As demonstrated in Figure 4E, quantitative analysis of the migrated cells based on Transwell indicated that the levels of cell migration were significantly higher for the $\mathrm{S}+\mathrm{B} @ \mathrm{P}$ group than for the $\mathrm{B} @ \mathrm{P}$ and PCL groups. Subsequently, we evaluated the potential of each group to 
A
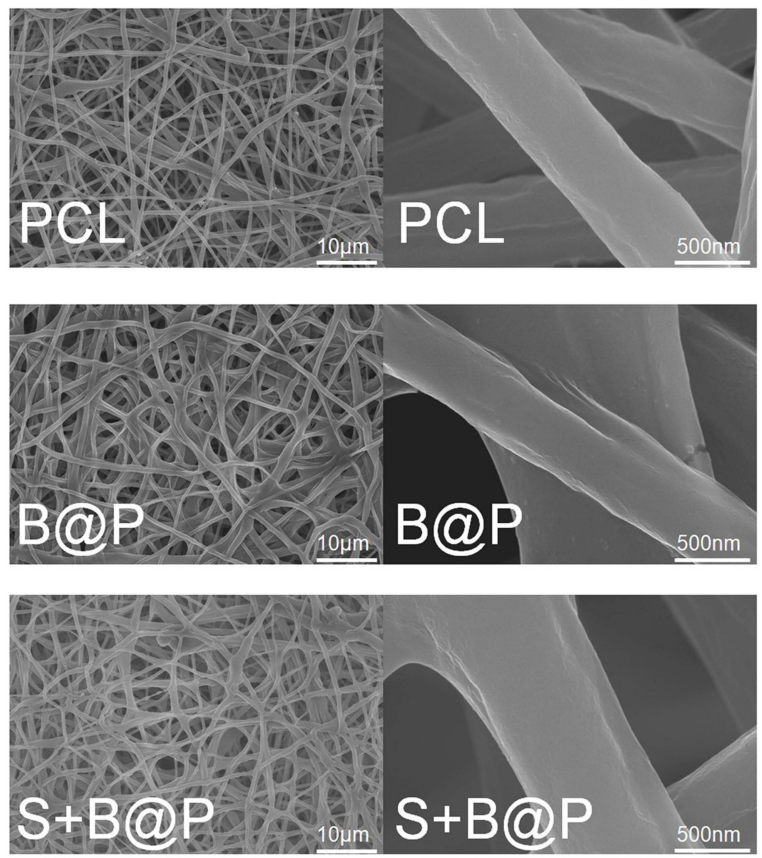

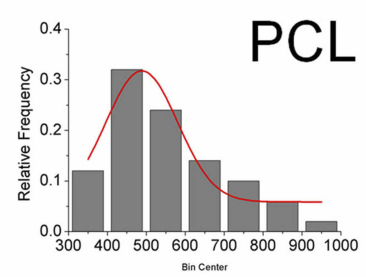

B
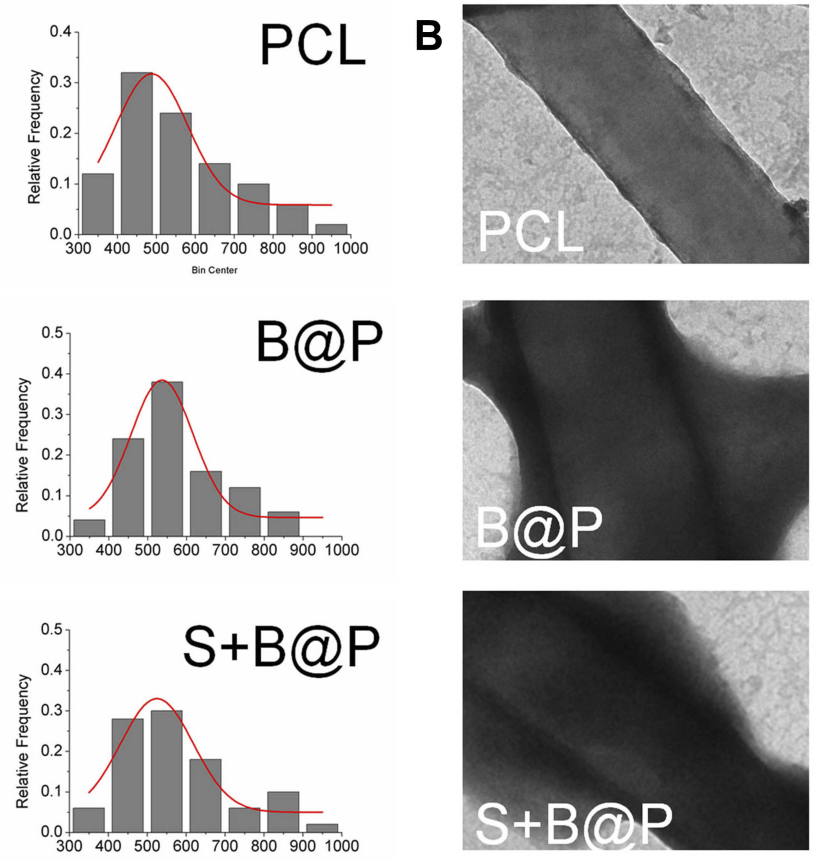

C

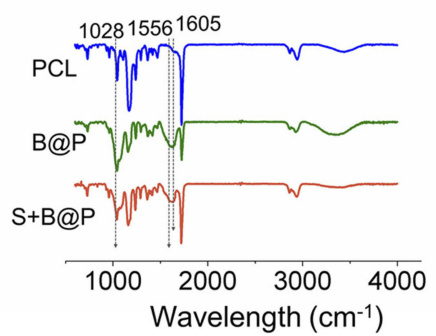

D

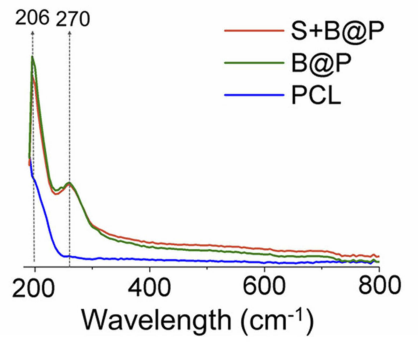

$\mathbf{E}$

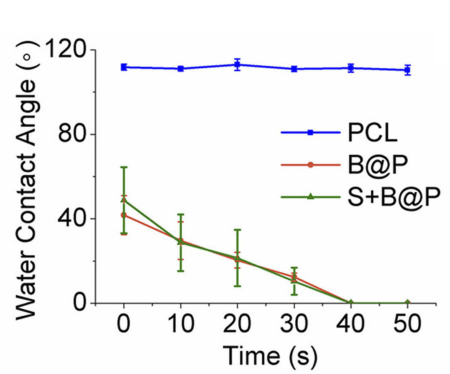

$\mathbf{F}$

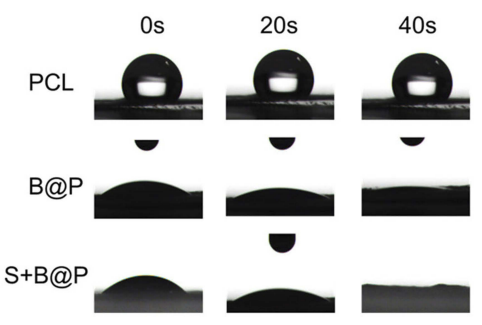

G

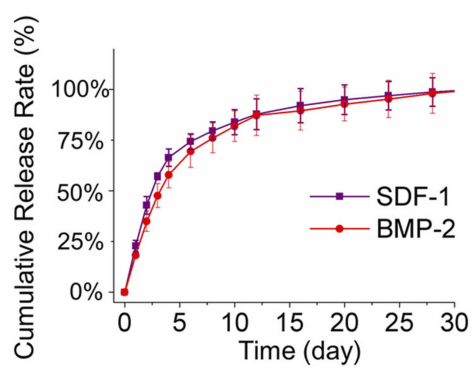

H

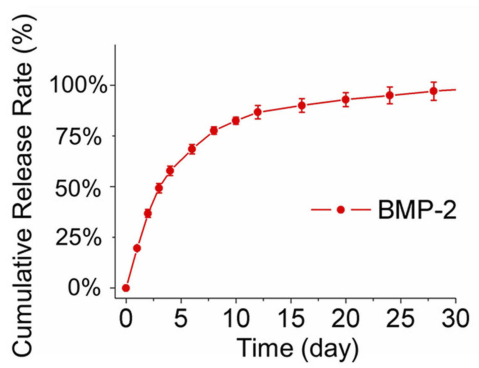

Figure 3 Characterization of $P C L, B @ P$ and $S+B @ P$.

Notes: (A) SEM image and nanofiber diameter distribution; (B) TEM images of the microstructure of nanofibers of PCL, B@P and S+B@P; (C) ATR-FTIR and (D) UV-vis analysis of PCL, B@P and S+B@P; (E) water contact angle curves decaying with time; (F) Live images of water droplets as a function of contact time; (G) In vitro SDF-I $\alpha$ and BMP-2 release profile from $\mathrm{S}+\mathrm{B} @ \mathrm{P} ;(\mathbf{H})$ In vitro BMP-2 release profile from $\mathrm{B} @ \mathrm{P}$.

Abbreviations: SEM, scanning electron microscope; TEM, transmission electron microscope; ATR-FTIR, attenuated total reflection flourier transformed infrared spectroscopy; UV-vis, UV-visible spectrophotometer.

induce the osteogenic differentiation of BMSCs in vitro. ALP is considered an important marker of osteogenesis, and a higher ALP secretion indicates a higher mineralization level of BMSCs. The results of ALP staining showed that extensive blue-violet deposition appeared in the $\mathrm{B} @ \mathrm{P}$ and $\mathrm{S}$ $+\mathrm{B} @ \mathrm{P}$ groups (Figure 4B), while the results of the quantitative detection of ALP demonstrated that the content of ALP in the S+B@P group was significantly higher than that in the PCL group (Figure 4F). Furthermore, the results of ARS indicated that after 30 days of osteogenesis induction in vitro, a high level of calcium deposition (red deposition) was found in the $\mathrm{B} @ \mathrm{P}$ and $\mathrm{S}+\mathrm{B} @ \mathrm{P}$ groups 

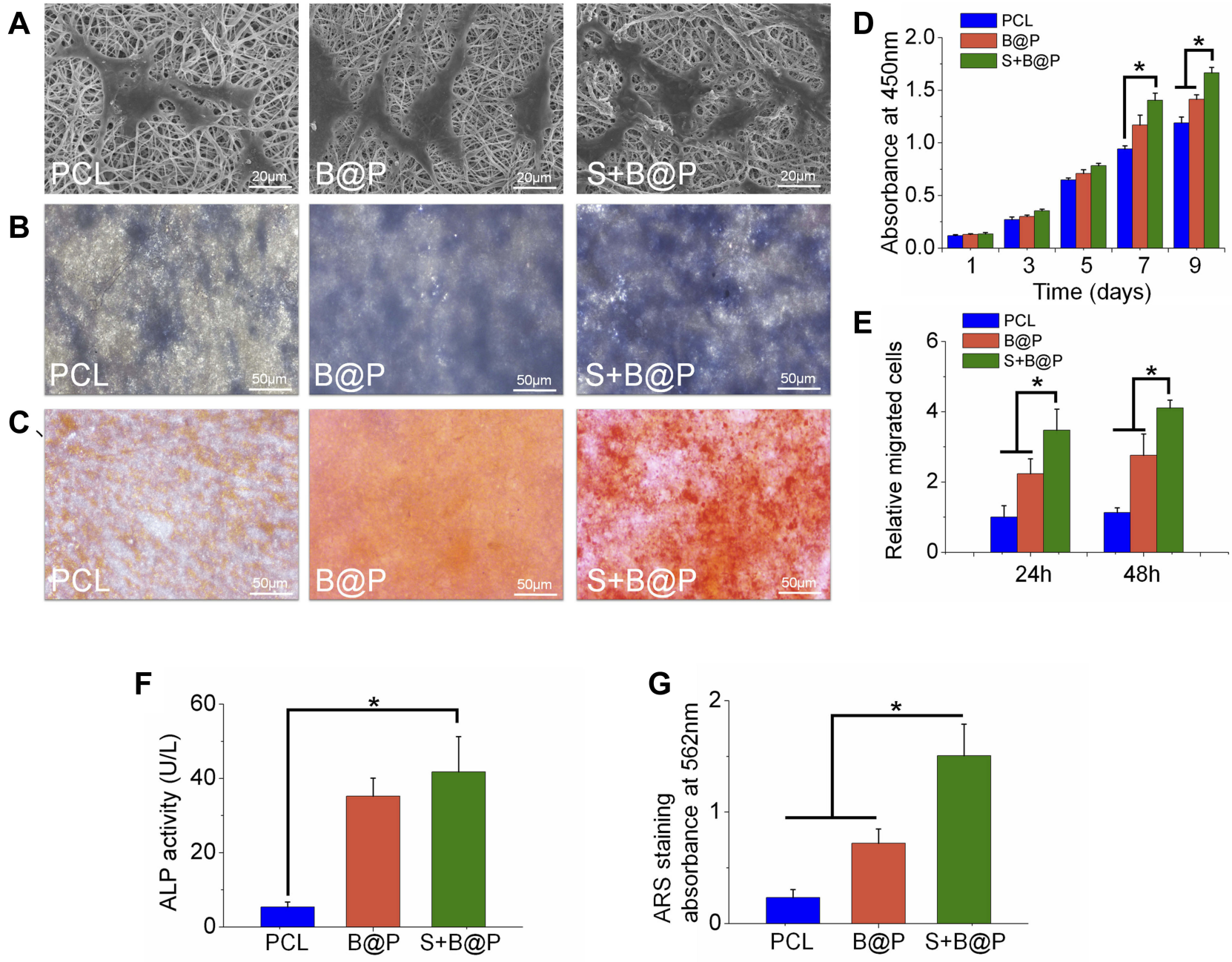

Figure 4 In vitro testing of BMSCs after cultured on each membrane (PCL, B@P and S+B@P).

Notes: (A) SEM images of BMSCs cultured on the membranes for $24 \mathrm{~h}$; (B) ALP staining images; (C) ARS staining images; (D) Cell viability of BMSCs cultured on the membranes as a function of culturing time; (E) Quantitative analysis of recruited cells based on Transwell; (F) Quantitative analysis of ALP; (G) Quantitative analysis of mineralized deposition based on ARS staining. (*P<0.05).

Abbreviations: BMSCs, bone marrow mesenchymal stem cells; ALP, Alkaline phosphatase; ARS, Alizarin red staining.

(Figure 4C). However, whereas many mineralized nodules were observed in the $\mathrm{S}+\mathrm{B} @ \mathrm{P}$ group, few mineralized nodules were found in the $\mathrm{B} @ \mathrm{P}$ group. Quantitative analysis of ARS confirmed that there were more mineralized deposits in the S+B@P group (Figure 4G). In addition, the local delivery of SDF-1 $\alpha$ and BMP-2 in S+B@P could regulate key genes of osteogenic differentiation in BMSCs in vitro (Figure 5). According to the results, the expression level of the Runx2 gene was significantly higher in the S+B@P group than in the other groups after the BMSCs were seeded on the scaffold for 7 days (Figure 5A). Additionally, after 14 days of culture, the gene expression levels of OCN, OPN, and COL I were higher in the $\mathrm{S}+\mathrm{B} @ \mathrm{P}$ group than in the other groups (Figure 5B-D). In general, the $\mathrm{S}+\mathrm{B} @ \mathrm{P}$ group is clearly the most capable of promoting the osteogenic differentiation of BMSCs.

\section{Histological Analysis}

To confirm the feasibility of the S+B@P scaffold for promoting the healing of autologous grafts and bone, both ends of an autologous Achilles tendon were wrapped with the S+B@P membrane and then implanted into the bone tunnel of a femur and tibia by ACL reconstruction surgery in a rabbit model. At 4 and 8 weeks after surgery, the interface between the autograft and the host bone tunnel was observed by H\&E staining as well as Masson's staining (Figure 6A and B). Obviously, some inflammatory cells infiltrated into the interface 4 weeks 

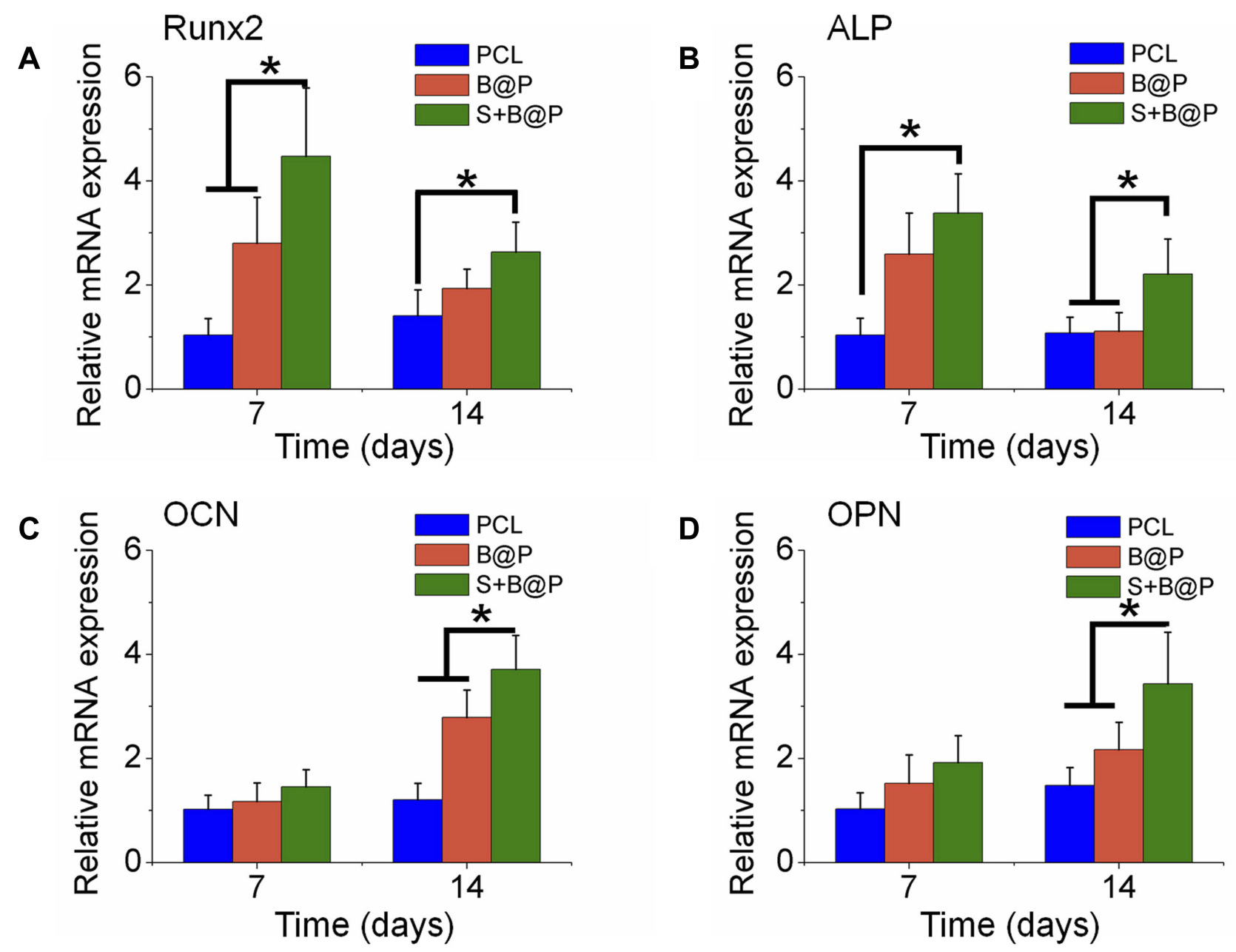

Figure 5 Quantitative PCR analysis.

Notes: The expression of osteogenic differentiation related genes, Runx2 (A), ALP (B); OCN (C) and OPN (D) were detected by Q-PCR after culturing BMSCs on the membranes for 7 and 14 days. $(* \mathrm{P}<0.05)$.

Abbreviations: Runx2, runt-related transcription factor 2; Col I, collagen I; OPN, osteopontin; OCN, osteocalcin.

after the ACL reconstruction surgery, which was a normal healing phenomenon, and these cells almost disappeared after 8 weeks. Additionally, thin fibrous scar tissue was formed in the tendon-bone interface in the S+B@P group. Notably, at 8 weeks after surgery, in the S+B@P group, a large amount of new bone formed inside the autograft, which demonstrated that the bone tunnel was healing and the tendon-bone integration was good. In the B@P group, although the fibrous scar tissue was thin, the autograft attached to the bone tightly, and there was less new bone formation at the interface, which indicates poor tendon-bone integration. However, in the PCL group, there was still more fibrous scar tissue at the interface, no significant mineralization was observed, and many membranes remained. In addition, immunohistochemical staining was utilized in this work for labelling osteogenic markers (including OCN and OPN) in the tissue samples, and the results are shown in Figure $6 \mathrm{C}$ and D. More brown precipitates indicated that more markers were stained. In the S+B@P group, at 4 and 8 weeks, the secretion of OCN and OPN in the bone tunnel always remained at a high level. The secretion of OPN in the B@P group was high at 4 weeks but dropped significantly at 8 weeks, which means that the level of new bone formation was relatively higher in the $\mathrm{S}+\mathrm{B} @ \mathrm{P}$ group. In general, these results of the histological experiments demonstrated that the local delivery of SDF- $1 \alpha$ and BMP-2 from the membrane was capable of promoting bone tunnel healing and tendon-bone interface integration. More importantly, the membrane modified by the growth-factor-loaded coating can accelerate the fusion of the membrane to the autologous tendon as well as the 

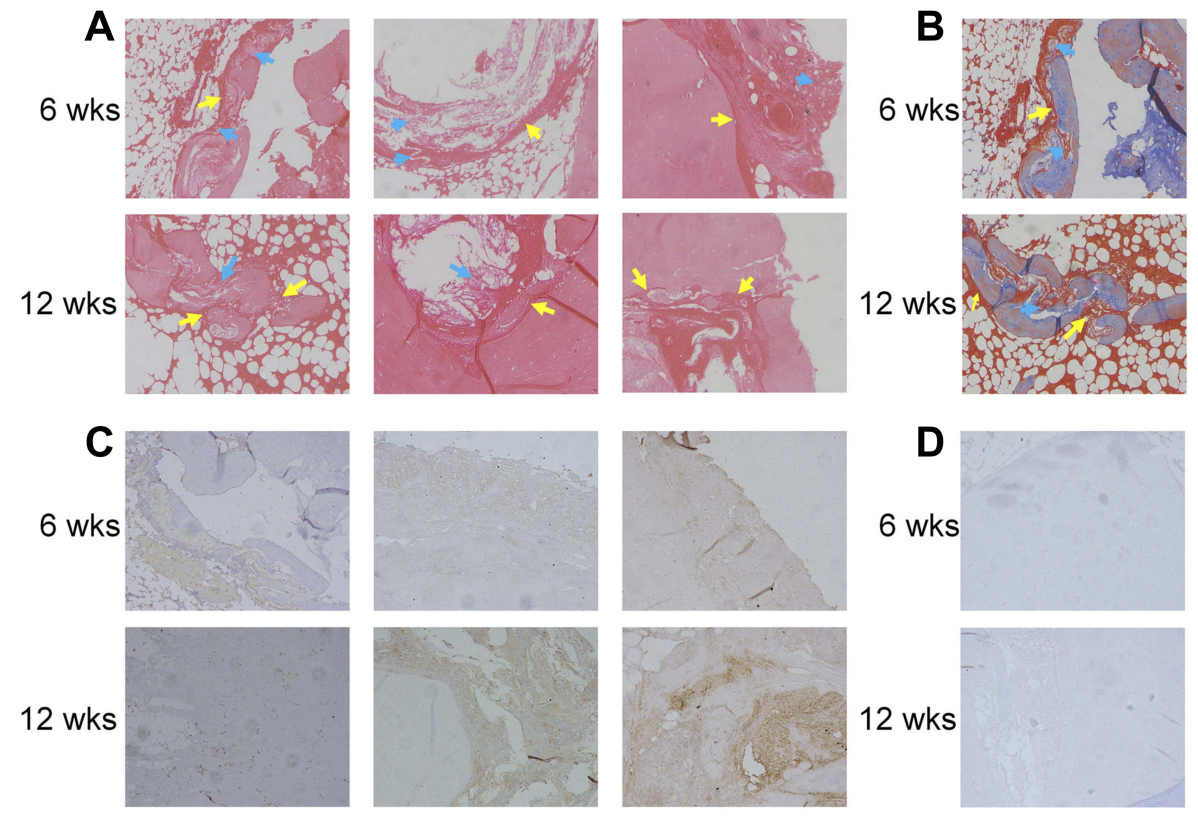

12 wks
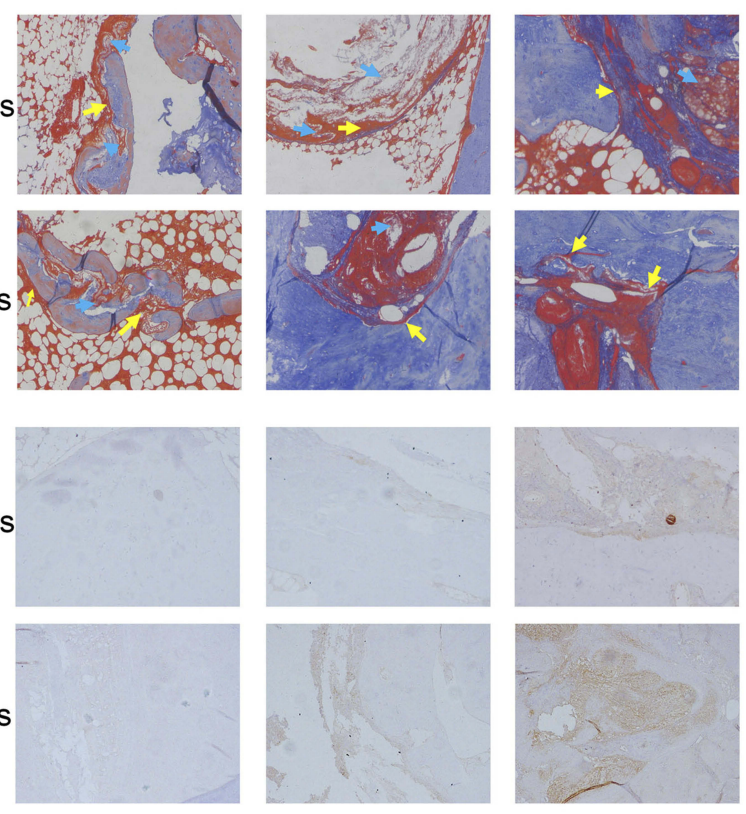

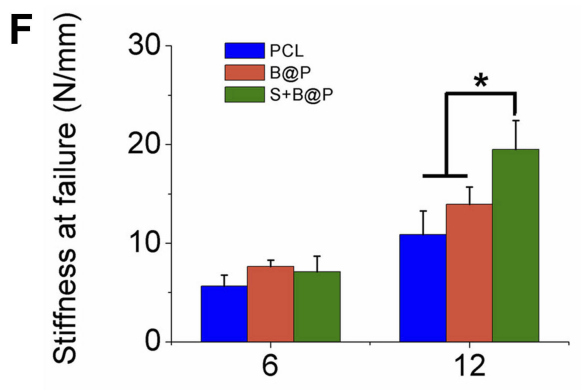

Time after surgery (weeks)

Figure 6 Analysis on histology and biomechanical features.

Notes: (A) H\&E and (B) Masson's staining of autograft tendon-bone interface 6 or 12 weeks after ACL reconstruction surgery in a rabbit model (blue arrow: undegraded membrane; yellow arrow: autograft tendon-bone interface); (C) Immunohistochemistry staining of OCN; (D) Immunohistochemistry staining of OPN; (E) Maximal failure force and $(\mathbf{F})$ stiffness of tendon-bone interface. ( $* \mathrm{P}<0.05)$.

Abbreviations: H\&E, hematoxylin-eosin; 6 wks, 6 weeks after surgery; 12 wks, 12 weeks after surgery.

degradation of the membrane, while the unmodified PCL membrane was not completely degraded after 8 weeks in vivo.

\section{Biomechanical Testing}

The biomechanical properties of the regenerative autograftbone interface in each group were evaluated using an Instron tension/compression system. Based on this system, the maximum failure force and stiffness of the graft can be detected, and the degree of interface integration between the autograft and bone can be inferred. At 8 weeks after surgery, the S+B@P group exhibited superior mechanical properties compared to those the B@P and PCL groups and had a failure force that was $25.8 \%$ higher than that of the $\mathrm{B} @ \mathrm{P}$ group and $87.1 \%$ of that of the PCL group (S+B@P vs B@P vs PCL: 79.9 vs vs 63.5 N, $\mathrm{p}<0.05$ ) (Figure 6E). Additionally, the stiffness of the $\mathrm{S}+\mathrm{B} @ \mathrm{P}$ group was $80.5 \%$ higher than that of the PCL group, and $40.3 \%$ higher than that of the $\mathrm{B} @ \mathrm{P}$ group (S+B@P vs B@P vs PCL: 19.5 vs 13.9 vs $10.8 \mathrm{~N} / \mathrm{mm}, \mathrm{p}<0.05$ ) (Figure $6 \mathrm{~F}$ ). These results confirmed that the local delivery of SDF-1 $\alpha$ and BMP-2 effectively improved the biomechanical properties of the interface.

\section{Discussion}

Histologically, "enthesis" refers to a special transitional series of tissues in the ligament-to-bone interface, which is characterised by a structure consisting of three regions, including the ligament/tendon, fibrocartilage/calcified fibrocartilage, and bone. $^{25}$ This distinct structure is critical for stress transfer between connective tissue and bone tissue. ${ }^{26}$ However, regenerating the native enthesis between the allograft and host bone 
tunnel after ACL reconstruction is difficult. Several studies have unveiled that the allograft and bone tunnel possess poor spontaneous healing ability and that the regenerative tissue in the tendon-bone interface mostly consists of poorly organized Sharpey-like fibers. ${ }^{27}$ Unfortunately, this regenerative tissue has inferior biochemical properties and is inefficient for maintaining the stability of the autograft in bone tunnels. Eventually, poor tendon-to-bone healing could increase the risk of graft slippage and reinjury. ${ }^{28}$ Another reason for hampered tendon-to-bone healing is peri-tunnel bone loss, which may result in bone tunnel widening, graft laxity, and infiltration of the joint fluid into the bone tunnel and even osteoarthritis. $^{7,8,29}$ Therefore, a successful graft-bone healing process requires timely tendon-bone interface integration to reduce the risk of surgical failure and enable the patients to quickly resume physical activity.

SDF-1 $\alpha$, which belongs to the chemokine CXC family, is a functional homeostatic chemokine that is secreted by immune cells in the early stage of the bone regeneration process and promotes the migration of circulating stem cells, such as BMSCs, to injured sites. ${ }^{30,31}$ In addition, due to its excellent capability of promoting the osteogenic differentiation of stem cells, BMP-2 has been widely applied for promoting bone defect healing and regeneration. Although the results of some studies show that BMP2-loaded scaffolds for bone regeneration are satisfactory, BMP-2 acts primarily in the late stage of the bone regeneration process. Until recent years, researchers have focused on the initial steps of bone regeneration and homeostatic chemokine-induced BMSC recruitment in injured sites. ${ }^{31,32}$ Studies have demonstrated that scaffolds loaded with dual growth factors (SDF-1 $\alpha$ and BMP-2) have excellent therapeutic effects on bone repair. ${ }^{20,33-35}$ In particular, although the release of SDF- $1 \alpha$ alone has a limited effect on promoting bone regeneration, the release of SDF- $1 \alpha$ and BMP-2 can synergistically promote the osteogenic differentiation and bone regeneration induced by BMP-2. ${ }^{20}$ Therefore, the objective of this study is to design a flexible multilayered scaffold loaded with SDF-1 $\alpha /$ BMP-2 that is suitable for assisting allograft grafting into the bone tunnel. We hypothesized that this membrane can accommodate the narrow space of the tendon-bone interface and locally release SDF-1 $\alpha / \mathrm{BMP}-$ 2. Due to the synergism of the released dual growth factors, the membrane has the capability of enhancing robust tendon-bone healing and integration and inhibiting fibrous scar tissue growth at the interface.
Based on our previous studies, ${ }^{36,37}$ a nanofibrous PCL membrane loaded with SDF- $1 \alpha$ and BMP-2 was fabricated ( $\mathrm{S}+\mathrm{B} @ \mathrm{P})$. By using LbL, the CS/HA multilayer coating was successfully established on the surface of the nanofiber, and the growth factor was tightly bound to the coating by electrostatic force. SEM was utilized to analyze the morphology of the nanofibers. After coating with CS/HA polyelectrolyte multilayers, the diameter of the nanofibers increased, forming a core-shell structure. In addition, the WCA data show that the hydrophilicity of the membrane was improved. This improvement occurred because with the progress of LbL self-assembly, a large amount of CS and HA with hydrophilic groups (amine, carboxyl and hydroxyl groups) adsorbed on the fiber, enhancing the hydrophilicity of the membrane. Our study investigated the effect of the local delivery of SDF- $1 \alpha$ and BMP-2 from the $\mathrm{S}+\mathrm{B} @ \mathrm{P}$ scaffold on the migration and osteogenic differentiation of BMSCs, as well as on allograft-bone tunnel healing in vivo. Compared with the $\mathrm{B} @ \mathrm{P}$ group with only BMP-2 loaded into the scaffold, the S+B@P group showed good BMSC migration efficiency and activity in vitro. According to the results of ALP \& ARS analysis, we surprisingly discovered that the $\mathrm{S}+\mathrm{B} @ \mathrm{P}$ scaffold could enhance the osteogenic differentiation of BMSCs via the synergism of SDF-1 $\alpha$ and BMP-2. Additionally, as the real-time PCR results showed, the expression of the transcription factor Runx 2 was enhanced and prolonged in the $\mathrm{S}+\mathrm{B} @ \mathrm{P}$ group, leading to the enhanced expression of Col I, which marks osteogenesisrelated extracellular matrix (ECM) maturation; eventually, the expression of the bone mineralization marker OCN was dramatically enhanced. These results demonstrated that $\mathrm{S}+\mathrm{B} @ \mathrm{P}$ can promote the migration of circulating BMSCs to the tendon-bone interface via the release of SDF-1 $\alpha$. Subsequently, the recruited BMSCs were exposed to BMP-2 released by $\mathrm{S}+\mathrm{B} @ \mathrm{P}$ and efficiently initiated BMP signaling and transduction in downstream pathways.

To test the capability of this membrane for promoting tendon-bone healing in vivo, we established a rabbit ACL injury model and wrapped both ends of an autogenous tendon graft using the membrane for ACL reconstruction. According to the results of the histological experiments, at 4 weeks after surgery, the $\mathrm{S}+\mathrm{B} @ \mathrm{P}$ group showed little fibrous tissue formation, and the autograft attached to the bone tunnel tightly; however, the boundary line between the allograft and bone was very obvious, which means that the tendon-bone interface was not integrated. In the PCL 
and B@P groups, more fibrous scar tissue formation and remaining scaffolds were observed at the interface. At 8 weeks postoperatively, in the $\mathrm{S}+\mathrm{B} @ \mathrm{P}$ group, there was a large amount of new bone formation in the interface and in the autograft, which means that the interface had begun to be integrated. This finding means that bone tissue, rather than fibrous scar tissue, grows extensively in the interface and into the autologous tendon, firmly "holding" the tendon and improving the biomechanical properties of the interface, as evidenced by the results of biomechanical testing. These data are of clinical significance for the treatment of ACL injury.

\section{Conclusion}

Generally, these data are of clinical significance for the treatment of ACL injury. Due to the synergism of the released dual growth factors, the membrane has the capability of enhancing robust tendon-bone healing and integration and inhibiting fibrous scar tissue growth at the interface. Furthermore, the biomechanics of the reconstructed ACL were improved. Therefore, this biomimetic nanofibrous membrane is applicable in clinical practice. Some researchers believe that the spatiotemporal release of SDF- $1 \alpha$ and BMP-2 can achieve better results than a mixed release. Therefore, in our future research, we will develop a biomimetic membrane based on $\mathrm{S}$ $+\mathrm{B} @$ P that can spatiotemporally release dual growth factors for ACL reconstruction.

\section{Acknowledgments}

This work was supported by the National Natural Science Foundation of China [81702122], Shanghai Municipal Natural Science Foundation (18ZR 1442100) and National Basic Research Program of China [2014CB964600]. The authors have no other relevant affiliations or financial involvement with any organization or entity with a financial interest in or financial conflict with the subject matter or materials discussed in the manuscript apart from those disclosed. No writing assistance was utilized in the production of this manuscript.

\section{Disclosure}

The authors report no conflicts of interest in this work.

\section{References}

1. Murawski CD, van Eck CF, Irrgang JJ, Tashman S, Fu FH. Operative treatment of trimary anterior cruciate ligament rupture in adults. J Bone Joint Surg Am. 2014;96A(8):685-694. doi:10.2106/JBJS. M.00196
2. Hewett TE, Di Stasi SL, Myer GD. Current concepts for injury prevention in athletes after anterior cruciate ligament reconstruction. Am J Sports Med. 2013;41(1):216-224. doi:10.1177/0363546512459638

3. Mall NA, Chalmers PN, Moric M, et al. Incidence and trends of anterior cruciate ligament reconstruction in the United States. Am J Sports Med. 2014;42(10):2363-2370. doi:10.1177/0363546514542796

4. Ajuied A, Wong F, Smith C, et al. Anterior cruciate ligament injury and radiologic progression of knee osteoarthritis: a systematic review and meta-analysis. Am J Sports Med. 2014;42(9):2242-2252. doi: $10.1177 / 0363546513508376$

5. Pinczewski LA, Lyman J, Salmon LJ, Russell VJ, Roe J, Linklater J. A 10-year comparison of anterior cruciate ligament reconstructions with hamstring tendon and patellar tendon autograft - A controlled, prospective trial. Am J Sports Med. 2007;35(4):564-574. doi:10.1177/ 0363546506296042

6. Yasuda K, Kondo E, Ichiyama H, et al. Anatomic reconstruction of the anteromedial and posterolateral bundles of the anterior cruciate ligament using hamstring tendon grafts. Arthroscopy. 2004;20 (10):1015-1025. doi:10.1016/j.arthro.2004.08.010

7. Samitier G, Marcano AI, Alentorn-Geli E, Cugat R, Farmer KW, Moser MW. Failure of anterior cruciate ligament reconstruction. Arch Bone Jt Surg. 2015;3(4):220-240.

8. Lui PPY, Lee YW, Mok TY, Cheuk YC, Chan KM. Alendronate reduced peri-tunnel bone loss and enhanced tendon graft to bone tunnel healing in anterior cruciate ligament reconstruction. Eur Cell Mater. 2013;25:78-96. doi:10.22203/eCM

9. Ekdahl M, Wang JHC, Ronga M, Fu FH. Graft healing in anterior cruciate ligament reconstruction. Knee Surg Sports Traumatol Arthrosc. 2008;16(10):935-947. doi:10.1007/s00167-008-0584-0

10. Liu G-M, Pan J, Zhang Y, et al. Bridging repair of large rotator cuff tears using a multilayer decellularized tendon slices graft in a rabbit model. Arthroscopy. 2018;34(9):2569-2578. doi:10.1016/j.arthro.2018.04.019

11. Liu Q, Hatta T, Qi J, et al. Novel engineered tendon-fibrocartilagebone composite with cyclic tension for rotator cuff repair. J Tissue Eng Regen Med. 2018;12(7):1690-1701. doi:10.1002/term.v12.7

12. Han F, Zhang P, Sun Y, Lin C, Zhao P, Chen J. Hydroxyapatite-doped polycaprolactone nanofiber membrane improves tendon-bone interface healing for anterior cruciate ligament reconstruction. Int J Nanomedicine. 2015;2015(10):7333-7343.

13. Zhi Y, Liu W, Zhang P, Jiang J, Chen S. Electrospun silk fibroin mat enhances tendon-bone healing in a rabbit extra-articular model. Biotechnol Lett. 2016;38(10):1827-1835. doi:10.1007/s10529-0162158-4

14. Ahmad Z, Rushton N. Extruded collagen fibres and biphasic collagen sponge for rotator cuff tendon repair application: an ovine in vitro study. Muscles Ligaments Tendons J. 2018;8(4):544-551.

15. Islam A, Bohl MS, Tsai AG, Younesi M, Gillespie R, Akkus O. Biomechanical evaluation of a novel suturing scheme for grafting load-bearing collagen scaffolds for rotator cuff repair. Clin Biomech. 2015;30(7):669-675. doi:10.1016/j.clinbiomech.2015.05.007

16. Schoenenberger AD, Foolen J, Moor P, Silvan U, Snedeker JG. Substrate fiber alignment mediates tendon cell response to inflammatory signaling. Acta Biomater. 2018;71:306-317. doi:10.1016/j. actbio.2018.03.004

17. Olvera D, Sathy BN, Carroll SF, Kelly DJ. Modulating microfibrillar alignment and growth factor stimulation to regulate mesenchymal stem cell differentiation. Acta Biomater. 2017;64:148-160. doi:10.1016/j.actbio.2017.10.010

18. Ji W, Yang F, Ma J, et al. Incorporation of stromal cell-derived factor-1 alpha in PCL/gelatin electrospun membranes for guided bone regeneration. Biomaterials. 2013;34(3):735-745. doi:10.1016/ j.biomaterials.2012.10.016

19. Kimura Y, Miyazaki N, Hayashi N, et al. Controlled release of bone morphogenetic protein-2 enhances recruitment of osteogenic progenitor cells for de novo generation of bone tissue. Tissue Eng Part A. 2010;16(4):1263-1270. doi:10.1089/ten.tea.2009.0322 
20. Shen X, Zhang Y, Gu Y, et al. Sequential and sustained release of SDF-1 and BMP-2 from silk fibroin-nanohydroxyapatite scaffold for the enhancement of bone regeneration. Biomaterials. 2016;106:205-216. doi:10.1016/j.biomaterials.2016.08.023

21. Smith RC, Riollano M, Leung A, Hammond PT. Layer-by-Layer platform technology for small-molecule delivery. Angew Chem Int Ed. 2009;48(47):8974-8977. doi:10.1002/anie.v48:47

22. Jin S, Li JD, Wang J, et al. Electrospun silver ion-loaded calcium phosphate/chitosan antibacterial composite fibrous membranes for guided bone regeneration. Int J Nanomedicine. 2018;13:4591-4605. doi:10.2147/IJN.S167793

23. Song YJ, Ma AB, Ning J, et al. Loading icariin on titanium surfaces by phase-transited lysozyme priming and layer-by-layer self-assembly of hyaluronic acid/chitosan to improve surface osteogenesis ability. Int J Nanomedicine. 2018;13:6751-6767. doi:10.2147/IJN.S174953

24. Kujawa P, Moraille P, Sanchez J, Badia A, Winnik FM. Effect of molecular weight on the exponential growth and morphology of hyaluronan/chitosan multilayers: a surface plasmon resonance spectroscopy and atomic force microscopy investigation. J Am Chem Soc. 2005;127(25):9224-9234. doi:10.1021/ja044385n

25. Lu HH, Thomopoulos S. Functional attachment of soft tissues to bone: development, healing, and tissue engineering. Yarmush ML, editor. Annu Rev Biomed Eng. 2013;15:201-226. doi:10.1146/ annurev-bioeng-071910-124656

26. Liu YX, Thomopoulos S, Birman V, Li JS, Genin GM. Bi-material attachment through a compliant interfacial system at the tendon-tobone insertion site. Mech Mater. 2012;44:83-92. doi:10.1016/j. mechmat.2011.08.005

27. Tabuchi K, Soejima T, Kanazawa T, Noguchi K, Nagata K. Chronological changes in the collagen-type composition at tendon-bone interface in rabbits. Bone Joint Res. 2012;1(9):218-224. doi:10.1302/2046-3758.19.2000109

28. Rothrauff BB, Tuan RS. Cellular therapy in bone-tendon interface regeneration. Organogenesis. 2014;10(1):13-28. doi:10.4161/org.27404
29. Wang J, Wu Y, Li H, et al. Magnesium alloy based interference screw developed for ACL reconstruction attenuates peri-tunnel bone loss in rabbits. Biomaterials. 2018;157:86-97. doi:10.1016/j.biomaterials. 2017.12.007

30. Mishima Y, Lotz M. Chemotaxis of human articular chondrocytes and mesenchymal stem cells. J Orthop Res. 2008;26(10):1407-1412. doi:10.1002/jor.20668

31. Andreas K, Sittinger M, Ringe J. Toward in situ tissue engineering: chemokine-guided stem cell recruitment. Trends Biotechnol. 2014;32 (9):483-492. doi:10.1016/j.tibtech.2014.06.008

32. Ko IK, Lee SJ, Atala A, Yoo JJ. In situ tissue regeneration through host stem cell recruitment. Exp Mol Med. 2013;45. doi:10.1038/ emm.2013.118

33. Herberg S, Aguilar-Perez A, Howie RN, et al. Mesenchymal stem cell expression of SDF-1 synergizes with BMP-2 to augment cell-mediated healing of critical-sized mouse calvarial defects. J Tissue Eng Regen Med. 2017;11(6):1806-1819. doi:10.1002/term.2078

34. Sun H, Wang J, Deng F, et al. Co-delivery and controlled release of stromal cell-derived factor-1 alpha chemically conjugated on collagen scaffolds enhances bone morphogenetic protein-2-driven osteogenesis in rats. Mol Med Rep. 2016;14(1):737-745. doi:10.3892/ mmr.2016.5339

35. Zwingenberger S, Langanke R, Vater C, et al. The effect of SDF-1 on low dose BMP-2 mediated bone regeneration by release from heparinized mineralized collagen type I matrix scaffolds in a murine critical size bone defect model. J Biomed Mater Res A. 2016;104 (9):2126-2134. doi:10.1002/jbm.a.35744

36. Huang D, Lin C, Wen X, Gu S, Zhao P. A potential nanofiber membrane device for filling surgical residual cavity to prevent glioma recurrence and improve local neural tissue reconstruction. PLoS One. 2016;11(8):e0161435

37. Li W, Zhao P, Lin C, et al. Natural polyelectrolyte self-assembled multilayers based on collagen and alginate: stability and cytocompatibility. Biomacromolecules. 2013;14(8):2647-2656. doi:10.1021/bm4005063
International Journal of Nanomedicine

\section{Publish your work in this journal}

The International Journal of Nanomedicine is an international, peerreviewed journal focusing on the application of nanotechnology in diagnostics, therapeutics, and drug delivery systems throughout the biomedical field. This journal is indexed on PubMed Central, MedLine, CAS, SciSearch ${ }^{\mathbb{B}}$, Current Contents ${ }^{\mathbb{B}} /$ Clinical Medicine, $^{2}$
Journal Citation Reports/Science Edition, EMBase, Scopus and the Elsevier Bibliographic databases. The manuscript management system is completely online and includes a very quick and fair peer-review system, which is all easy to use. Visit http://www.dovepress.com/ testimonials.php to read real quotes from published authors. 